\title{
Interannual variability of Black Sea's hydrodynamics and connection to atmospheric patterns.
}

\author{
Capet Arthur ${ }^{\mathrm{a}, *}$, Barth Alexander ${ }^{\mathrm{a}}$, Beckers Jean-Marie ${ }^{\mathrm{a}}$, Marilaure Gregoire ${ }^{\mathrm{b}}$ \\ ${ }^{a}$ GeoHydrodynamics and Environmental Research, University of Liège, B5a, 17 allée du 6 Aout, 4000 Liège, Belgium \\ ${ }^{b}$ Oceanology Laboratory, University of Liège, B6c, 3 allée de la chimie, 4000 Liège, Belgium
}

\begin{abstract}
The long term variability (1962-2000) of the Black Sea physical processes (e.g. temperature, main circulation, cold intermediate layer, sea level) and its relation to atmospheric conditions and large scale climate patterns are investigated using an eddy-resolving tridimensional model in combination with statistical tools (e.g Empirical Orthogonal Functions, Self Organizing Maps). First, the ability of the model to represent the interannual dynamics of the system is assessed by comparing the modeled and satellite sea surface temperature (SST) and sea level anomaly (SLA) decomposed into their dominant Empirical Orthogonal Functions (EOFs). The correlation between the spatial and temporal EOFs modes derived from model and satellite is usually satisfactory and this gives some confidence in using the model as a tool to investigate not only the SST and SLA dynamics but also the dynamics of connected variables.

Then, the long term variability (1962-2000) of the Black Sea hydrodynamics is assessed by decomposing into their dominant EOFs modeled SST, SLA and selected key hydrodynamical variables associated to the main circulation and vertical structure of the water column. Significant correlations between the EOFs associated to these variables are investigated in order to link the variability of surface fields and the internal dynamics of the system.

In particular, the intensity of the general cyclonic circulation (the Rim current) is shown to impact strongly on (1) the mean sea level, (2) the SST response to air temperature (AT), (3) the formation of the cold intermediate layer, (4) the meridional repartition of the SST anomaly and (5) the exchanges of heat between the north-western shelf and the open basin.

In order to appraise the variability of atmospheric conditions over the Black Sea during 1962-2000 and their role in driving the hydrodynamics, a self-organizing maps technique is used in order to identify spatial recurrent patterns of atmospheric fields (ie. AT, wind stress and curl).

The impact on these patterns of large scale climatic variability over the north Atlantic, the Eurasia and Pacific Ocean (estimated by respectively the north Atlantic oscillation (NAO), the east Atlantic/west Russia oscillation (EA/WR) and the El Niño southern oscillation (ENSO) indexes) is assessed. Distinct time scales of influence of the large scale teleconnection patterns on the AT are identified : EA/WR drives the short scale (1-5 years) variations of SST, while the long term ( $>5$ year) trends of the NAO drive the long term SST trends.

The drastic changes that have occurred in the Black Sea deep sea ecosystem at the end of the 80's are connected to an intensification of the general circulation which has promoted an export of riverine materials from the eutrophicated north-western shelf to the deep sea.

Finally, in the last two decades, we find an increased duration of persistent atmospheric anomalies regime that have the potentials to drive the system away from its average state as occurred in the late $80 \mathrm{~s}$. If persistent in the future, such long lasting atmospheric anomalies may have a significant impact on the ecosystem functioning.
\end{abstract}

Keywords: Black Sea, Inter-annual variability, Rim current, SST

\footnotetext{
${ }^{*}$ Corresponding author. Tel:+32 43663648 ; Fax:+32 43669729

Email addresses: arthurcapet@gmail.com (Capet Arthur), a.barth@ulg.ac.be (Barth Alexander), jm.beckers@ulg.ac.be (Beckers Jean-Marie), mgregoire@ulg.ac . be (Marilaure Gregoire)
} 


\section{Introduction}

[1] The important river discharge characterizing the almost enclosed Black Sea, combined with the import of salty Mediterranean waters through the Bosphorus, result in a strong permanent halocline which restricts the "active part" to upper $\sim 150 \mathrm{~m}$. This confinement makes the Black Sea surface layer particularly sensitive to changing environmental conditions.

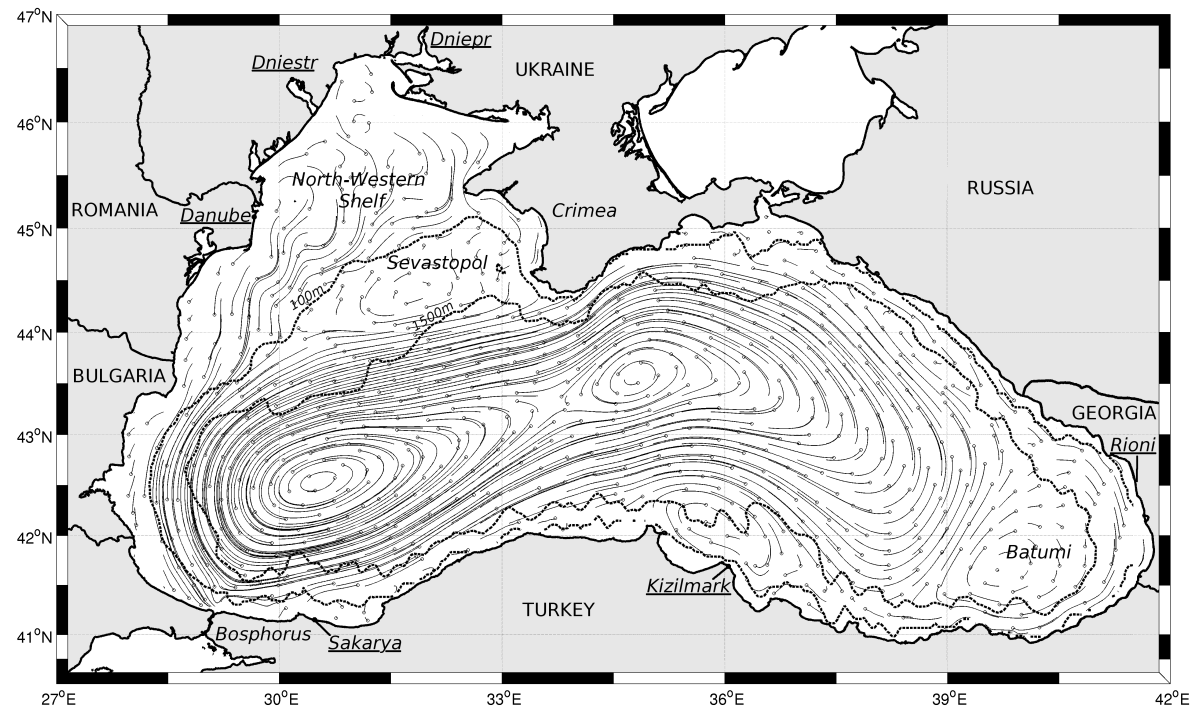

Figure 1: The Black Sea surface circulation, as simulated by the model used in this study, in May (climatological 1962-2000). The 6 main rivers considered in the model are underlined, the 100 and $1500 \mathrm{~m}$ depth contours are depicted in dotted line. During May, the Batumi and Sevastopol anticyclonic gyres, which are important structures of the Black Sea circulation (as discussed in the text) are well visible.

[2] The north-western part of the Black Sea (i.e. the north-western shelf denoted in the following as the NWS) consists of an almost 200-km wide shelf representing about $13 \%$ of the total area and receiving the fresh water inputs of the Danube, Dnestr and Dnepr rivers (the Danube being by far the most important river bringing about $75 \%$ of the total river input into the whole sea). The surface circulation consists of a persistent cyclonic coastal current referred as the Rim current (Figure 1). Between this main current and the coast, a number of seasonal anticyclonic eddies develop. The Batumi eddy in the extreme East of the basin and the Sevastopol eddy situated above the NWS slope, West of the Crimea peninsula are the most permanent mesoscale structures of the Black Sea (Staneva et al., 2001; Korotaev et al., 2003). The permanent halocline is dome-shape, due to the geostrophic dynamics associated with the Rim current. This curvature is enhanced in winter by the intensification of the Rim current. In summer, a seasonal thermocline creates a double pycnocline structure which allows the existence of the cold intermediate layer (CIL), a layer of minimal temperature situated between the halocline and the thermocline and defined by the $8^{\circ} \mathrm{C}$ isosurfaces. Two important regions of formation coexist for the dense and cold waters constituting the CIL (CIW). The first one, accounting for $\sim 42 \%$ (Stanev et al., 2003) of the annual CIW production, is a small area West of the Crimea peninsula, where the strong winter cooling is accompanied by the possibility of mixing with underlying salty waters (the latter is not true for the northernmost NWS area where surface cooling is however more important). The second area, in the northern part of the central basin, accounts for 28\% (Stanev et al., 2003) of the annual CIW production. Surface cooling in this area is not as important as on the NWS, but the outcropping of the deep isopycnals, associated with the winter intensification of the Rim current, allow the cooling to penetrate directly to the density levels of the CIL.

[3] The Black Sea region is located at the edge of various atmospheric systems and their relative influences combine differently over the seasons and over the years, leading to abrupt and significant changes of the weather conditions (Cherneva et al., 2008). Teleconnection patterns are often invoked to account for these different weather conditions (e,g. Krichak et al., 2002; Oguz et al., 2006; Kazmin and Zatsepin, 2007). They refer to large-scale (hemisphere) coherent modes of variation in the distribution of atmospheric masses. These have been growingly used in the scientific literature, since they have potentials to explain large scale correlations in the variations of weather conditions, oceanic 
conditions and consequent ecosystem changes (e.g. Niermann et al., 1999). Although the north Atlantic Oscillation (NAO) has been found to have a strong impact on the Mediterranean weather (e.g. Hurrell and Deser, 2010), and on the Black Sea hydrodynamics (e.g. Stanev and Peneva, 2002; Ginzburg et al., 2004; Oguz et al., 2006) the east Atlantic/west Russia (EA/WR) pattern (alternatively called the North-Sea/Caspian pattern (Kutiel and Benaroch, 2002)) has been found to be better associated to the Black Sea sea surface temperature (SST) during some years (Oguz et al., 2006). The El Niño southern Oscillation (ENSO) was found by Ginzburg et al. (2004) to promote in the Black Sea the occurrence of extreme (i.e. minima's and maxima's) SST values.

[4] Through the last decades, the Black Sea ecosystem, and particularly its NWS has been the scene of drastic changes (e.g. eutrophication, collapse of fish stock, alien species invasion) with important consequences for the surrounding economies (Mamaev and Zaitsev, 1997; Langmead et al., 2009). It clearly appears that only the combination of human pressures (overfishing, riverine pollution, alien species introduction, ...) with natural decadal modulation of the hydrodynamic structure allows to explain these severe ecosystem shifts (Oguz and Gilbert, 2007; Llope et al., 2011).

[5] The main aims of this paper can be summarized as follows: (1) to assess and understand the variability of the Black Sea physical conditions at interannual and decadal scales and in particular, to connect the variability of surface fields (i.e. SST, sea level anomaly (SLA)) with the internal dynamics of the system, (2) to estimate the impact of atmospheric conditions over the Black Sea on the dynamics of the system, (3) to link the variability of atmospheric fields with large scale climate variability, (4) to examine the existence of a trends in SST during the period 1962-2000 and the effect of global warming in general, (5) to connect the variability of the Black Sea physical environment to the drastic changes in the ecosystem that mainly occurred at the end of the 80's.

[6] More specifically, a 3D hydrodynamical model is used to provide at high resolution (5km) and at basin scale synoptic physical variables (temperature, salinity, velocity, sea surface height (SSH), Energy). The ability of the model to simulate the interannual variability of the Black Sea hydrodynamics is first assessed by comparing the SST and SLA provided by the model and by satellite. The 4 dominant EOFS of modeled and satellite SST and SLA are compared by estimating the correlation between the spatial and temporal EOFs. As shown in this study, this level of validation allows assessing the performances of the model in representing surface fields but also the internal dynamics of the system. Then, long term simulations are performed in order to assess the variability of the Black Sea hydrodynamics at interannual and decadal scales. The variability of SST, SLA, CIL cold content, Rim current intensity, vertical mixing is estimated through a EOFs decomposition of these variables. Corresponding variabilities from different variables are identified by correlation analysis between their dominant EOFs. This allows to connect processes and to understand the internal dynamics of the system.

[7] We identify recurrent typical patterns of atmospheric conditions over the Black Sea area over the period 19622000 and we assess the impact on these patterns of large scale climatic variability associated with the atmospheric systems over the north Atlantic, the Eurasia and Pacific Ocean (estimated by respectively the NAO, EAWR and ENSO indexes).

[8] The innovative aspects of the work can be summarized as follows. (1) In previous studies, the assessment of the long term variability of the Black sea physical properties is assessed using either satellite data (e.g. Stanev and Peneva, 2002; Ginzburg et al., 2004; Nardelli et al., 2010; Grayek et al., 2010) or in-situ data (e.g. Oguz et al., 2006; Oguz and Gilbert, 2007). Both approaches have its own limitations: satellite SST are only available since 1985 while in situ observations have a limited spatial coverage and are not ideal to take into account the spatial variability of the system which is very important especially in the NWS region. Here, the model represents the spatial variability of the system at high resolution $(5 \mathrm{~km})$. (2) This study quantifies the correlations between the variability of several physical processes and this allows to gain an enhanced and integrated understanding of the Black Sea internal dynamics at interannual and decadal scales as well as its connection with atmospheric conditions over the Black Sea. (3) Most of the time the spatial structure of atmospheric fields is ignored and the impact of climate indexes is usually not quantified appropriately but rather is estimated based on the similarity of variability of basin scale average fields and climate indices. Here, a SOM analysis of atmospheric conditions provides recurrent spatial patterns of air temperature (AT), wind stress and curl. Keeping the spatial information allows further understanding than provided by the study of basin average values (Kazmin and Zatsepin, 2007). The impact of large scale climate conditions on atmospheric patterns is assessed through a statistical test. (4) The deterministic model presented in this study is run without any data assimilation and can then be used for scenarios studies.

[9] The paper is organized as follows. The model is briefly described in section 2. Section 3 describes and compares 
the modeled and satellite derived SST and SLA main modes of variability (EOFs) and assesses the ability of the model to correctly reproduce the different levels of variability of these surface variables. Section 4 analyzes over the period 1962-2000 the main modes of variability of the simulated fields decomposed into their dominant EOFs. Correlations between the temporal EOFs associated to different variables are investigated in order to propose a physical meaning to the different EOFs modes. This allows to link the dynamics of surface properties with the internal functioning of the system. Section 5 is devoted to the analysis of atmospheric conditions and identifies recurrent regimes of AT and wind circulation anomalies. General relationships with teleconnection indexes are depicted in this section. Results from the previous sections are discussed in section 6 and in particular, the question of a potential impact of climate change is addressed. Conclusions and perspectives are given in section 7.

\section{The 3D model}

[10] The GHER3D general circulation model has been successfully applied to explore the general circulation of the North Sea (Delhez, 1996), the Mediterranean Sea (Beckers, 1991; Barth et al., 2005) and the Black Sea (Grégoire et al., 1998; Beckers et al., 2002; Grégoire and Friedrich, 2004; Vandenbulcke et al., 2009).

[11] For the present implementation, the model is run on a regular Arakawa-C grid of resolution $\Delta x=\Delta y=$ $0.045^{\circ}(5 \times 4 \mathrm{~km})$, using the terrain following double-sigma vertical coordinates system (Beckers, 1991). The open boundaries are restricted to the Bosphorus and the 6 main rivers : Danube, Dniepr, Dniestr, Rioni, Kizilmark and Sakarya. Annual values of the river flows are provided by Ludwig et al. (2009), as well as climatological seasonal repartitions used to construct the monthly river forcing. The parameterization of the Bosphorus is set up to ensure the representation of the two-layer exchange, needed to sustain the halocline, while ensuring long term conservation of total salt content and total water content.

[12] Atmospheric data used to force the model are issued from the ECMWF ${ }^{1}$ ERA40 reanalysis, available during 1996-2001, on a $1.125^{\circ}$ grid, using $2 \mathrm{~m}$ AT and dew point temperature, $10 \mathrm{~m}$ winds, sea level pressure and precipitations. Winds components are downscaled to $0.2^{\circ}$ by spline interpolation, which allows a better conservation of the wind curl. All atmospheric fields are filtered in order to suppress the erroneous influence of land points on the coastal sea conditions (Kara et al., 2007). The wind stresses, the heat fluxes and the pseudo fluxes of salt associated to evaporation and precipitation are computed interactively considering the state of the model surface layer. The model is run without any relaxation term or data assimilation.

[13] Analyzes of the integrated kinetic energy content (not shown) indicates that 2 years of spin-up are needed to recover from the climatological initial conditions. Results, saved as weekly averages, are thus considered over the 39 years period from 1962 to 2000.

\section{Satellite products and model validation}

[14] In this section, we describe the satellite SST and SLA data sets used to assess the ability of the model to simulate the interannual variability of the Black Sea. With this aim, modeled and satellite SST and SLA are decomposed into their dominant EOFs and these EOFs are compared (Appendix B).

[15] This comparison constitutes a rigourous and demanding assessment of the model performances in representing the successive orders of variability of the Black Sea hydrodynamics. The validation effort goes beyond a "classic" comparison of surface observable values since, as shown in the following, the various modes of variability of SST and SLA (estimated from the EOFs analysis) are significantly correlated to the internal dynamics of the system (e.g. CIL properties, mixing, circulation).

\subsection{Sea surface temperature}

[16] SST fields measured by Advanced Very High Resolution Radiometer (AVHRR) are provided by NOAA ${ }^{2}$ and are processed by Nardelli et al. (2010). For comparison issues, weekly averages are computed from the daily satellite products while the model results are binned on the corresponding $1 / 16^{\circ}$ grid.

\footnotetext{
${ }^{1}$ European Center for Medium-Range Weather Forecasts (http://www . ecmwf . int/).

${ }^{2}$ National Atmospheric and Oceanic Administration (http://www.noaa.gov/).
} 
[17] The seasonal cycle represents almost $99 \%$ of SST variability, and largely overpasses the interannual variability (Nardelli et al., 2010). This study focuses on the interannual variability of the system and therefore, the validation exercise needs to assess the ability of the model to simulate processes at this scale. A typical seasonal cycle is extracted from model and satellite data as explained in Appendix A and the EOFs are computed on the obtained anomalies.
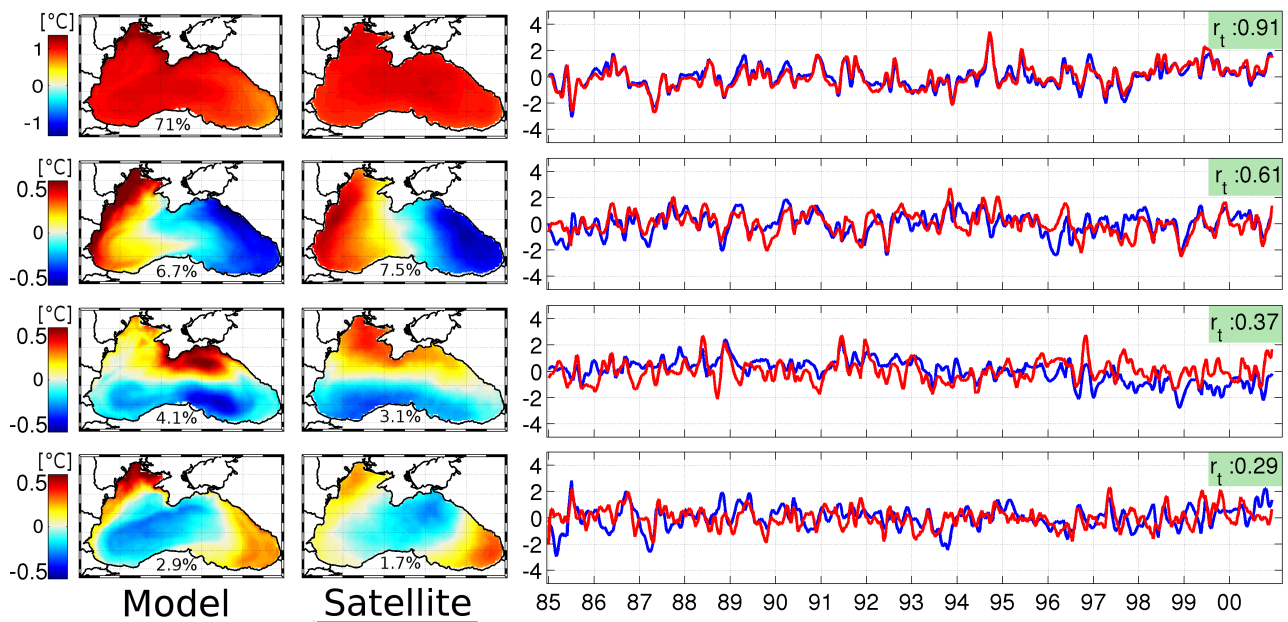

Figure 2: From top to bottom, the first EOFs of the SST anomalies (1985-2000) sorted by decreasing order of explained variability. From left to right: the spatial structure of the model EOF, the spatial structure of the satellite EOF and the associated temporal amplitudes (blue for model, red for satellite). The percentages of variability accounted for by the modes are indicated in the right corners of the spatial maps, while green boxes give the spatial $\left(r_{s}\right.$, on the left panels) and temporal $\left(r_{t}\right.$, on the right panels) Pearson correlation coefficients between the model and the satellite products.

[18] Figure 2 shows that, both in the model results and in the satellite data, the four dominant EOFs account together for $\sim 85 \%$ of the SST anomalies variability.

[19] The first mode explains more than $70 \%$ of the variability and corresponds to a basin scale increase/decrease of the SST anomaly (the spatial pattern has the same sign over the basin). The associated temporal EOFs are highly correlated $\left(r_{t}=0.91\right)$. The lower spatial correlation $\left(r_{s}=0.52\right)$ can be explained by the underestimation by the model of the variability in the Batumy area. Due to the low spatial variability of this first mode, the spatial correlation coefficient is more sensitive to small differences in variabilities in the modeled and satellite data set. It should be noted that this distinct SST variability in the Batumi region does not appear anymore when the EOFs are computed over the period 1962-2000 (see section 4, Figure 4) which suggests that it is specific to the 1985-2000 period.

[20] The second and third modes explain respectively 6-7 and 3-4 \% of the variability and correspond to respectively the modulations of the zonal and meridional gradient of the SST anomaly. Modeled and satellite EOFs are well correlated in space and time.

[21] The fourth mode explains less than $3 \%$ of the variability and while the modeled and satellite spatial patterns are well correlated, the temporal modes are weakly correlated indicating that this level of detail lies at the limit of model capability.

\subsection{Sea level anomaly}

[22] The SLA images are processed and distributed by the AVISO program ${ }^{3}$. These anomalies are computed with respect to the Mean Dynamical Topography (MDT)(CNES, 2011). As the MDT field is not directly available for the Black Sea, average SSH over the 1993-1999 period is taken as a proxy, and is subtracted from the modeled SSH to produce the model SLA which are then binned on the AVISO $1 / 8^{\circ}$ grid for comparison.

[23] In the case of SLA, interannual and seasonal variations present similar amplitudes. Furthermore, the seasonal cycle does not correspond to one EOF (as for SST) but rather is dispatched among the first two EOFs as also found

\footnotetext{
${ }^{3}$ Archiving, Validation, and Interpretation of Satellite Oceanographic data (http://www . aviso.oceanobs . com/index . php?id=1394).
} 


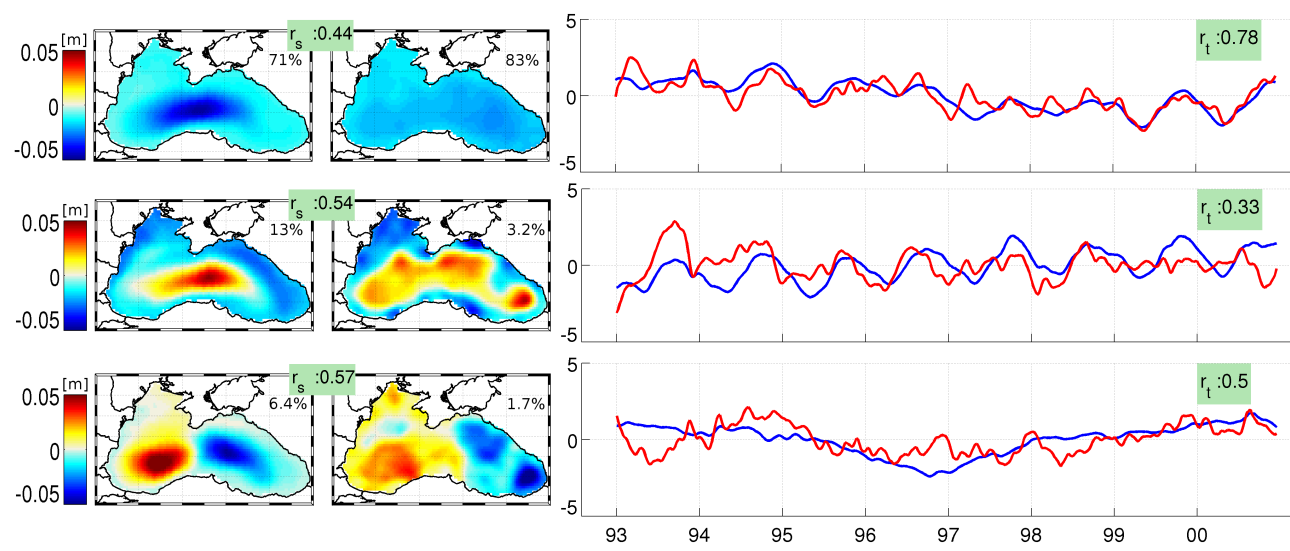

Figure 3: From top to bottom, the first EOFs of the SLA (1993-2000) sorted by decreasing order of explained variability. From left to right : the spatial structure of the model EOF, the spatial structure of the satellite EOF and the associated temporal amplitudes (blue for model, red for satellite). The percentage of variability accounted for by the modes are indicated in the right corner of the spatial maps, while green boxes give the spatial ( $r_{s}$, on the left panels) and temporal $\left(r_{t}\right.$, on the right panels) correlations between model and satellite products.

by Grayek et al. (2010). This prevents the clear identification of a climatological seasonal cycle over the period 19932000. Therefore, the EOF decomposition of modeled and satellite SLA over 1993-2000 is realized on the SLA rather than on the anomalies compared to a typical seasonal cycle as for SST (Figure 3).

[24] The first three modes of modeled and satellite SLA explain more than $88 \%$ of the SLA variability. For the first mode which accounts for $71 \%$ and $83 \%$ of the SLA variability in the model and the satellite data, respectively, the spatial pattern is homogeneous in sign and corresponds to a basin-wide rising or lowering of the sea surface with a maximum intensity in the center of the basin.

[25] This enhanced curvature is more pronounced in model results but has also been evidenced by Grayek et al. (2010), using the SLA produced by AVISO over a larger period (1993-2006).

[26] The second EOF presents a spatial structure characterized by an opposed variability between the coastal areas and the deep basin and is therefore associated to the variability of the curvature of the sea surface. The third EOF accounts for a difference in the zonal repartition of water masses, as detailed in (Grayek et al., 2010).

[27] For these two modes the model and satellite spatial EOFs are significantly correlated $\left(r_{s}>0.5\right)$ but, as in the case of SST, the satellite SLA presents a distinct variability in the Batumi area.

[28] The general lower variability in the modeled compared to the satellite SLA (compare the modeled and satellite temporal EOFs shown in Figure 3) can be explained by the absence of steric effects (Grayek et al., 2010) and of a volumetric impacts of precipitation and evaporation ${ }^{4}$ in the model. These two processes may add noise to the SLA response to circulation features. However, the correlation coefficients between modeled and satellite SLA are significant except in the case of the second mode $\left(r_{t}=0.33\right)$

\section{Long term model analysis}

[29] In this section the long term variability of the Black Sea hydrodynamics is analyzed using model results from a simulation over the 1962-2000 period. SST and SLA variabilities are connected to the internal dynamics by addressing a selection of key properties for the Black Sea : the mixed layer depth (MLD) (Kara et al., 2009), the cold intermediate layer cold content (CCC) (Stanev and Staneva, 2002) and the mean kinetic energy (MKE), as representative of the intensity of surface currents (please refer to Appendix $C$ for details about the computation of these quantities).

[30] The EOFs of each of these variables (including SST and SLA) are computed separately, after subtraction of their respective seasonal cycle and after applying a low pass filter (1-year moving average) on the anomalies. In this way, the responses to rapid variations of the Black Sea weather are filtered out and only anomalies with a time scale of one year or larger are considered.

\footnotetext{
${ }^{4}$ Precipitation and evaporation are represented trough pseudo fluxes of salinity rather than through volumetric variations.
} 
[31] Then, we estimate the Spearman rank correlation between the dominant EOFs of SST and SLA and those of the selected hydrodynamical variables. As this paper investigates the temporal variability, correlations are estimated between the temporal EOFs modes and variables that are correlated $(r>0.5, p<0.05)$ are presented in Figures 4,5 and 6.

[32] This section describes the modes and the correlations between them. For briefness, each EOF is referred by the acronym of the corresponding variable followed by the rank of the EOF (e.g. MLD-1 is the first mode of mixing layer depth). In section 6, we physically interpret the different modes of variability of the physical variables and try to connect them to atmospheric variables.

[33] SST-1 (Figure 4) is best linked with MLD-1 $(r=0.67)$ and CCC-1 $(r=0.6)$. Although the spatial patterns of these three modes differ, they all are homogeneous in sign and thus consist in synchronous basin-wide anomalies. It means that to a basin wide increase (resp. decrease) of the SST corresponds a decrease (resp. increase) of the MLD (counted in meter negatively from the surface), and a decrease (resp. increase) of the CCC (low CCC corresponds to a higher temperature in the CIL or to a smaller CIL volume).

[34] More specifically, SST-1 is rather homogeneous with an enhanced variability on the shallow NWS. MLD-1 and CCC-1 exhibit a spatial structure similar to the typical pattern of distribution of MLD: deeper on the periphery, in particular above the shelf slope West of Crimea and shallower in the central basin where a permanent rising of the halocline occurs. For these two variables, the region between the shelf slope and the Rim current presents an enhanced variability where a deepening of the MLD corresponds to an increase of the CCC.

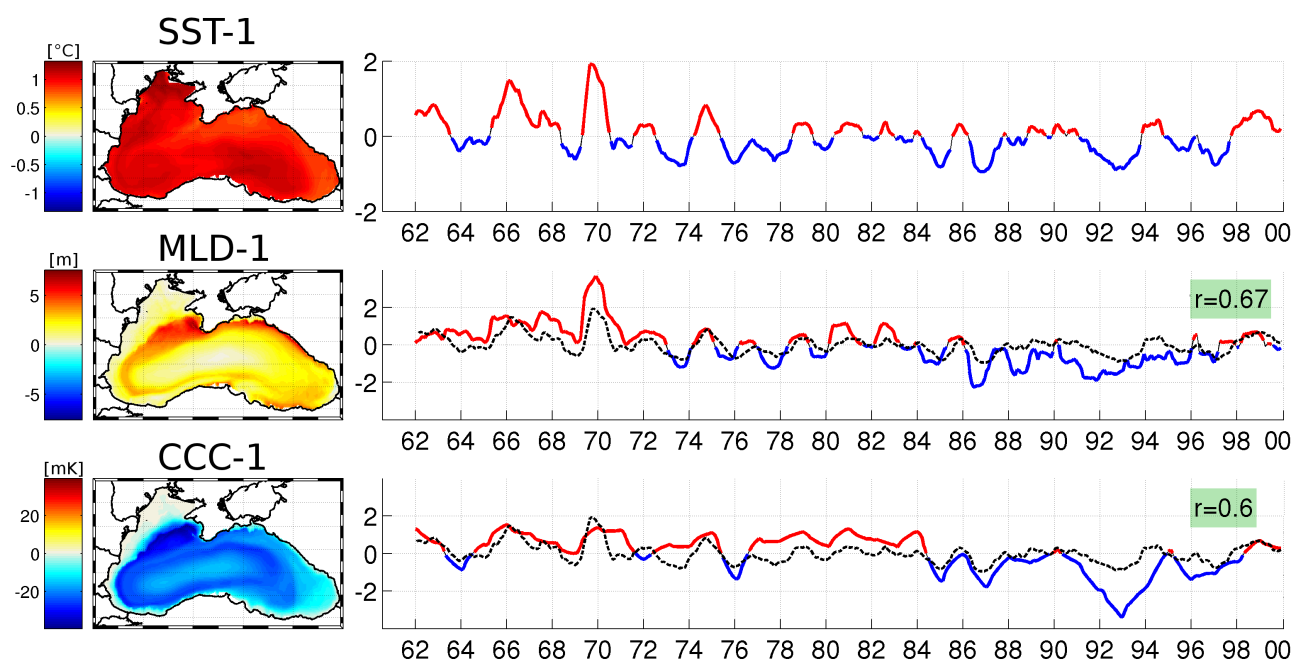

Figure 4: The first EOF of SST (SST-1) (top), MLD-1 (middle) and CCC-1 (bottom). Left: spatial components of the EOFs. Right: temporal components of the EOFs, with evidenced positive (red) and negative (blue) phases and with the Spearman rank correlation coefficient (green boxes) estimated with SST-1 (SST-1 reproduced in dotted lines).

[35] SST-2 only shows significant correlation with CCC-2 $(r=0.54)$. The spatial pattern of SST-2 exhibits an East/West front with temperature anomalies of opposite sign in the western and eastern basin. The interface is modulated by the influence of the Rim current. The spatial distribution of CCC-2 (Figure 5) evidences anomalies of opposite sign in the two main regions of CIL formation described in the introduction and identifies their area of influence.

[36] Figure 6 presents the EOFs correlated with SLA-1. The strongest correlation occurs with MKE-1 $(r=0.94)$, which is a proxy of the Rim current (as evidenced by its spatial pattern). The next best related EOFs are MLD-1 $(r=0.67)$, CCC-1 $(r=0.61)$ and SST-3 $(r=0.53)$.

\section{Atmospheric conditions}

[37] In this section, we analyze the variability of atmospheric conditions affecting the Black Sea region. Characteristic meteorological regimes are identified and related to the large-scale teleconnection patterns. Results of this section 


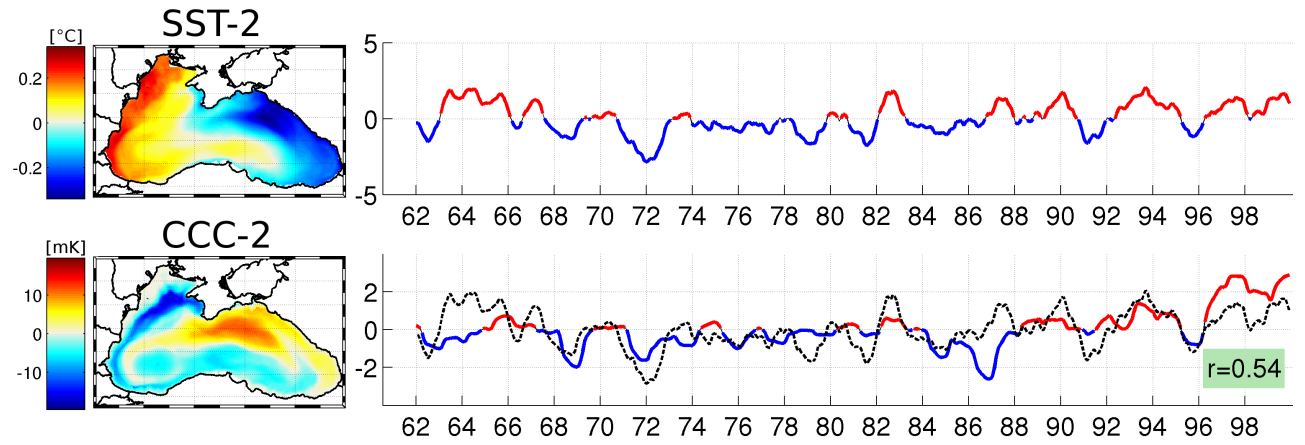

Figure 5: Second EOF of SST (SST-2, on the top) and CCC-2 (bottom). Left: spatial components of the EOFs. Right: temporal components of the EOFs, with evidenced positive (red) and negative (blue) phases and with the Spearman rank correlation coefficient (green boxes) estimated with SST-2 (SST-2 reproduced in dotted lines).

are used in section 6 in order to highlight the role of atmospheric conditions in driving the hydrodynamical modes identified in section 4 .

\subsection{Identification of recurrent atmospheric patterns}

[38] Coherently with the analysis of hydrodynamical variables, a typical seasonal cycle is first subtracted from the atmospheric data used to force the model (see section 2 and Appendix A), and then the obtained anomalies are smoothed by a 1-year moving average.

[39] Monthly averaged anomalies of AT, zonal and meridional wind speed and the wind curl are then jointly integrated in the Self Organizing Map (SOM) analysis (Appendix D), in order to identify recurrent spatial patterns of coincident anomalies of these various fields.

[40] The six typical spatial patterns identified by the SOM analysis are presented in figure 7 showing the winds components and the AT associated to each pattern. Additionally, and in order to familiarize the reader with the SOM concept, figure 8 presents for each month (from 1962-2000) the anomalies of the wind components and and indicates to which recurrent patterns (shown in Figure 7) these anomalies are mapped by the SOM procedure.

[41] Pattern 5 is characterized by the highest positive temperature anomalies and by southern winds (Figure 7) which are more often from the west as indicated by the position of pattern 5 in figure 8 which is slightly shifted on the right axis corresponding to westerlies.

[42] The lowest temperature anomalies are described by either pattern 1 or pattern 4 and are associated either to north-eastern winds (pattern 1) or north-western winds (pattern 4).

[43] The spatial repartition of the AT anomaly illustrated in Figure 7 shows that the NWS presents an enhanced positive anomaly compared to the rest of the basin in association with western winds (i.e. patterns 4 and 6) while an enhanced negative anomaly is associated with eastern winds (i.e. patterns 1 and 2). East winds have indeed been found to promote the westward extension of the cold air mass from the Siberian weather system (Shapiro et al., 2010a).

[44] South-western winds generate anticyclonic wind (positive curl) over the Black Sea (patterns 5,6) while northern winds promote a cyclonic circulation (patterns 1 and 4).

\subsection{Influence of the large scale teleconnection patterns}

[45] The potential impacts of large scale climate variability on the recurrent patterns of atmospheric conditions illustrated in Figure 7 is assessed by estimating for each recurrent pattern the value of the climate indexes (i.e. NAO, EAWR, ENSO) obtained for the different months mapped towards this pattern. This allows assessing whether a recurrent pattern is significantly associated to a positive or negative value of a climate index and hence a connection between atmospheric conditions over the Black Sea and large scale climate features. Monthly average values of the climate indexes are provided by the NOAA Climate Prediction Center ${ }^{5}$. 

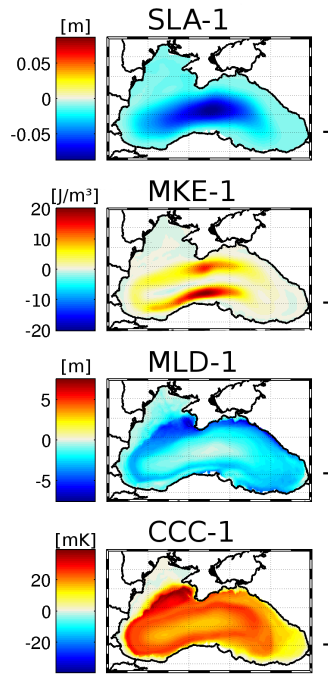

SST-3

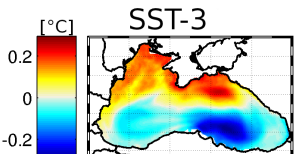

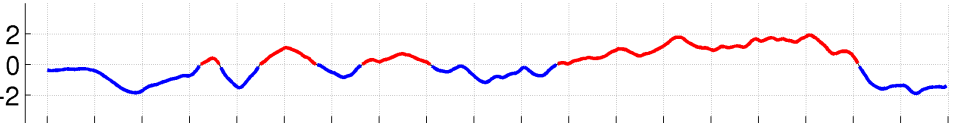

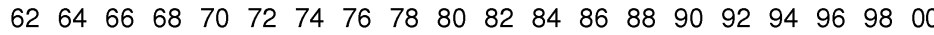

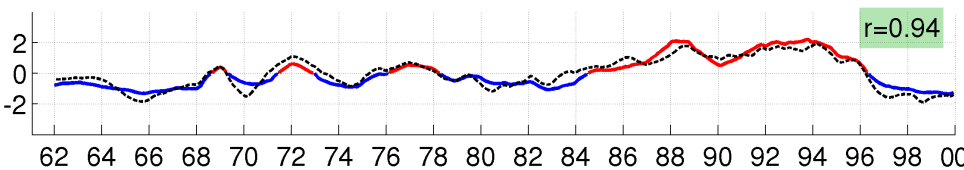

$\begin{array}{llllllllllllllllllll}62 & 64 & 66 & 68 & 70 & 72 & 74 & 76 & 78 & 80 & 82 & 84 & 86 & 88 & 90 & 92 & 94 & 96 & 98 & 00\end{array}$

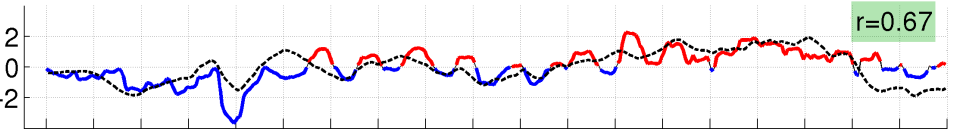

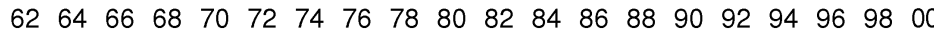

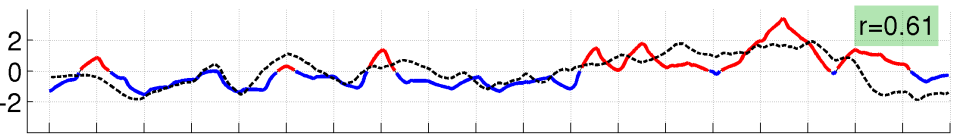

$\begin{array}{llllllllllllllllllll}62 & 64 & 66 & 68 & 70 & 72 & 74 & 76 & 78 & 80 & 82 & 84 & 86 & 88 & 90 & 92 & 94 & 96 & 98 & 00\end{array}$

$r=0.53$

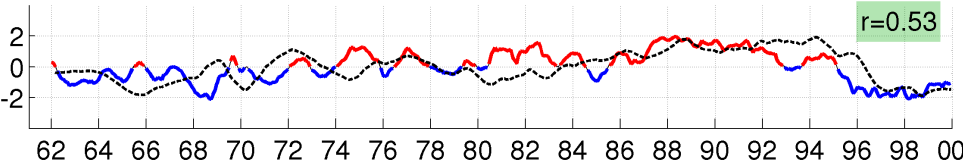

Figure 6: Top to bottom: First EOF of SLA (SLA-1), MKE (MKE-1), MLD (MLD-1), CCC (CCC-1), and third EOF of SST (SST-3). Left: spatial components of the EOFs. Right: temporal components of theEOFs, with evidenced positive (red) and negative (blue) phases and with the Spearman rank correlation coefficient (green boxes) estimated with SLA-1 (SLA-1 reproduced in dotted lines).
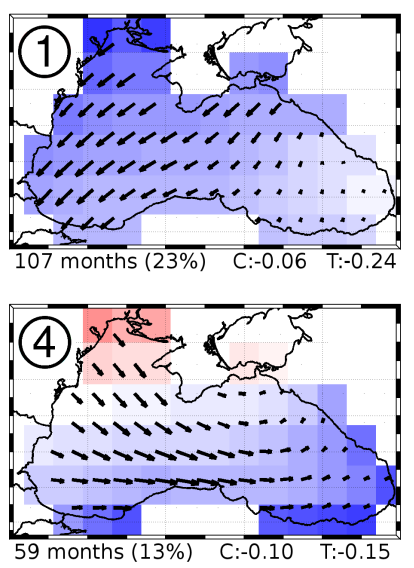
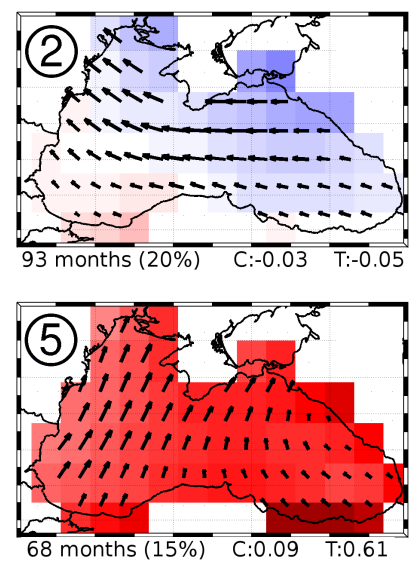
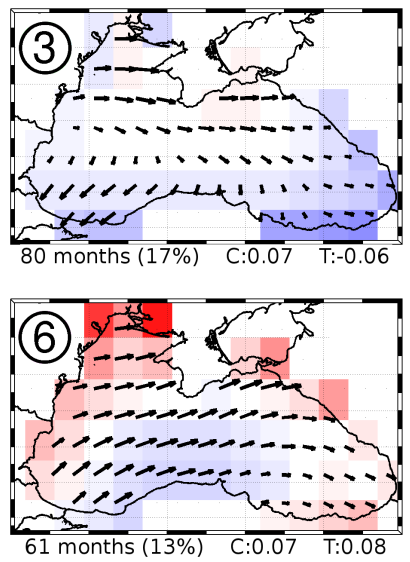

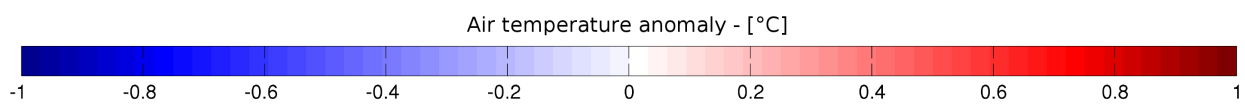

Figure 7: Typical patterns of the meteorological anomalies as identified by the SOM analysis for the period $1962-2000$ ( the encircled number on each panel labels the pattern for further references in the paper). At the bottom of each panel are indicated the number and percentage of months mapped toward this pattern, as well as the corresponding basin averaged wind curl $\left(\mathrm{C},\left[s^{-1}\right]\right)$ and $\mathrm{AT}\left(\mathrm{T},\left[{ }^{\circ} \mathrm{C}\right]\right)$ anomalies.

[46] Figure 10 indicates for each atmospheric pattern, the distribution of positive and negative phases of the three teleconnection indexes during the months mapped towards this atmospheric pattern.

[47] This Figure shows that the EA/WR index is significantly negative during months mapped towards patterns 2

\footnotetext{
5 http://www.cpc.ncep.noaa.gov/data/teledoc/telecontents.shtml
} 


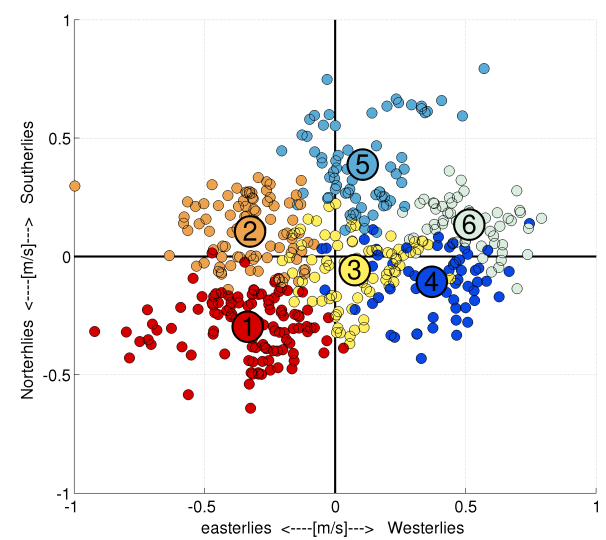

Figure 8: Monthly anomalies of meridional and zonal winds components (small circles, basin scale average values for all the months between 1962-2000). The larger circles locate the pattern identified by the SOM analysis. One color is associated to each pattern and the months mapped toward a given pattern have the same color.
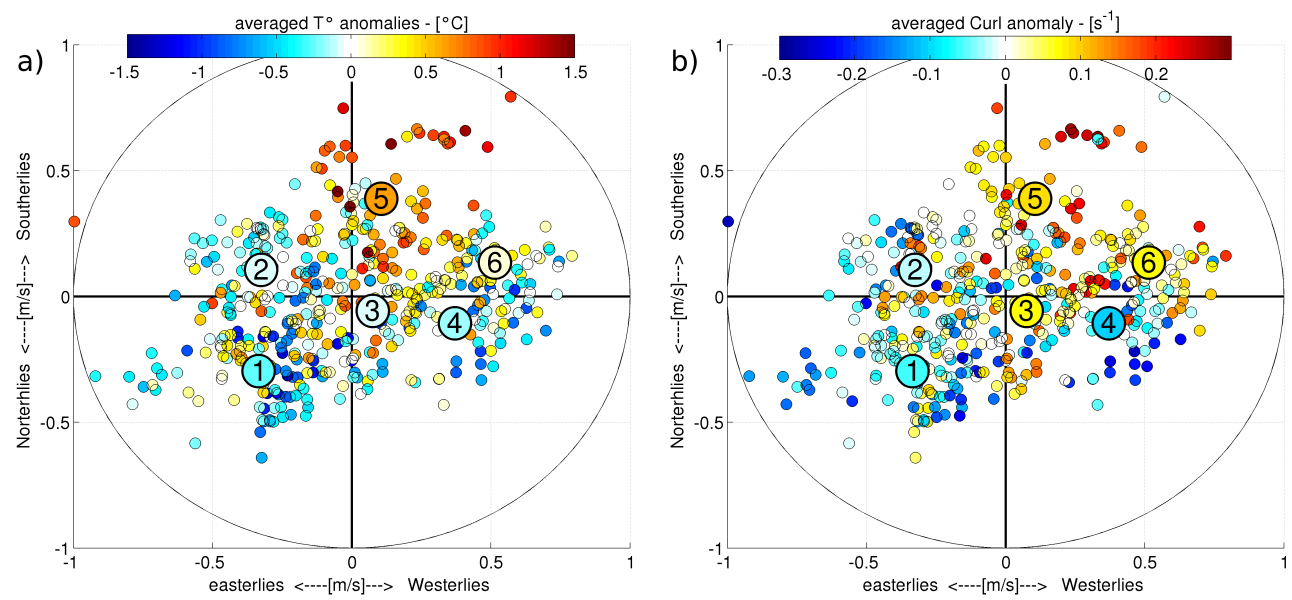

Figure 9: Small circles: monthly anomalies of the basin scale averaged of the meridional and zonal winds components (all the months between 1962-2000 are plotted). Large circles: recurrent patterns identified by the SOM analysis and illustrated in Figure 7 . Left: with the basin average AT anomaly superimposed. Right: with the basin average wind curl anomaly superimposed.

and 5 which means that this index promotes the occurrence of south-easterlies (pattern 2) and southerlies (pattern 5). EA/WR is significantly positive during months mapped towards patterns 1,3 and 4 characterized by the occurrence of northerlies. Therefore, EA/WR significantly impacts the occurrence of northerlies and southerlies and hence influences the AT anomaly as already described in section 5.1 and further analyzed in section 5.3.

[48] Strong positive NAO index are more frequent in patterns 4 and 6 characterized by western winds. The negative phase, however is not related to eastern winds but rather, amplifies the negative phase of EA/WR to promote extreme southern anomalies, as can be seen by comparing the cases of patterns 2 and 5. The highest wind curls (patterns 4 and 5) correspond to the most significant distribution of the NAO index among positive and negative values: cyclonic (resp. anticyclonic) wind fields being promoted by positive (resp. negative) phases. However this relationship between the NAO index and the wind curl can not be extended to moderate wind curl anomalies (patterns 1, 2, 3 and 6). Therefore, NAO significantly influences the occurrence of western winds and of extreme wind curls but is not systematically linked to anomalies of AT.

\subsection{Comparison with previous studies}

[49] Kazmin and Zatsepin (2007) found no relationships between the EA/WR index and the wind regimes, nor with 

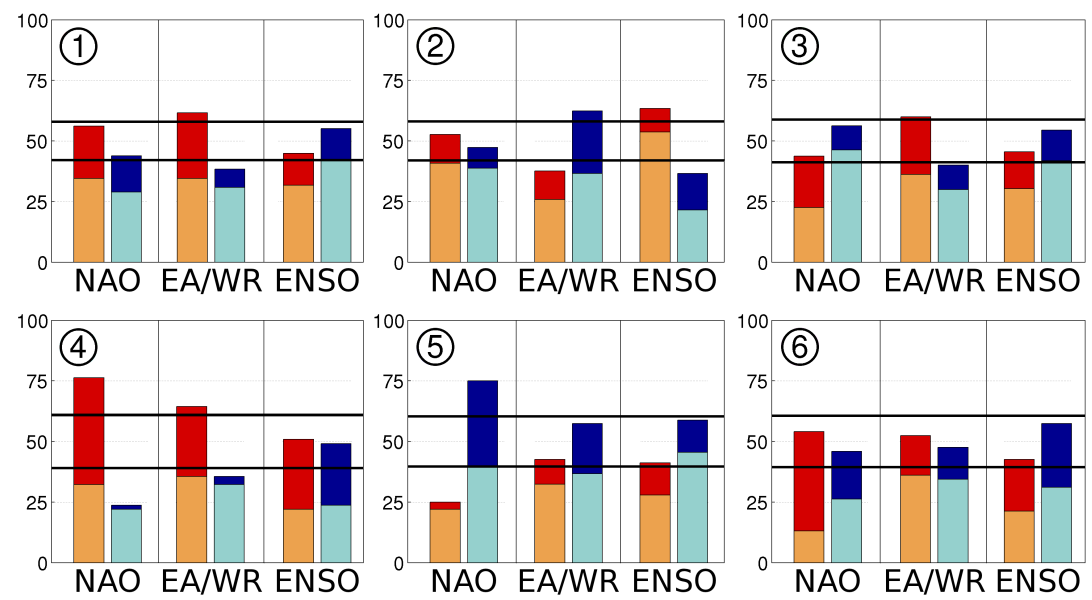

Figure 10: Distribution for each atmospheric pattern (identified in Figure 7, one panel by pattern) between positive (red) and negative (blue) phases of the teleconnections indexes. We conclude that the phase of an index has a significant $\left(\mathrm{p}_{i} 0.05\right)$ impact on the atmospheric pattern when its distribution amongst positive and negative values fall both outside the bold lines (see Appendix D for details).

the AT, while these relationship appear clearly in the present work. Conversely, they mentioned a relationship between NAO and AT, also evidenced in the work of Oguz et al. (2006) while this relationship is not found significant in the present work (see section 5.2). These different conclusions are not surprising and stress the influence of the spatial and temporal scales taken into account to perform this type of study. Indeed, conclusions depend notably whether the spatial variability of the atmospheric fields is considered or not (in Kazmin and Zatsepin (2007) basin wide averages are considered, here the spatial variability is considered), the type of temporal averages that have been performed (monthly in this study, seasonal in Kazmin and Zatsepin (2007)), the smoothing window (1 year in this study against 5 years in Kazmin and Zatsepin (2007), the removal of a seasonal cycle (in this study we are working with anomaly),

...

[50] To highlight the importance of these factors, Figure 11 illustrates the evolution over 1962-2000 of the basin averaged AT, NAO and EA/WR indexes after smoothing with a 1-year and 5-year average for comparison. It is shown that on a short term (1-5 years), the AT anomaly follows the oscillation of the EA/WR index while, the longer term trends of SST (>5 years), as those depicted by Ginzburg et al. (2004); Nardelli et al. (2010) seems to follow the trends of the NAO index. This partly reconciles the two studies. In fact, the impact of NAO may be indirect through an effect on the localization of EA/WR associated poles of sea level pressure anomaly as reported by Krichak et al. (2002).

[51] No systematic influence of the ENSO index could be deduced from the present analysis. This is in contradiction with Ginzburg et al. (2004) who found that the extreme anomalies of SST occur during the El Niño phases. The absence in this study of a clear relationship between ENSO and the atmospheric patterns identified in Figure 7 does not imply that ENSO has no impact on the Black Sea SST but if ENSO impacts the SST it is not through an air temperature anomaly resulting from modification of the winds pathways. Indeed, the recurrent atmospheric patterns identified by the SOM analysis correspond to coincident anomalies of the winds (direction and curl) and AT.

[52] An important remark in Oguz et al. (2006) reminds that the indexes values do not account for the relative positions of the teleconnection's centers of action. This oversimplification can explain some discrepancies in the results with the depicted relationships.

\section{Discussion}

[53] In this section we first discuss and interpret the different modes of variability of SST and SLA identified over the period 1962-2000 in connection with the variability of the hydrodynamics and of meteorological conditions and river discharges. A particular focus is put on the various impacts of the Rim current intensity. Then, this variability is connected with the drastic changes in the ecosystem that mainly occurred at the end of the 80s. Finally, we investigate 


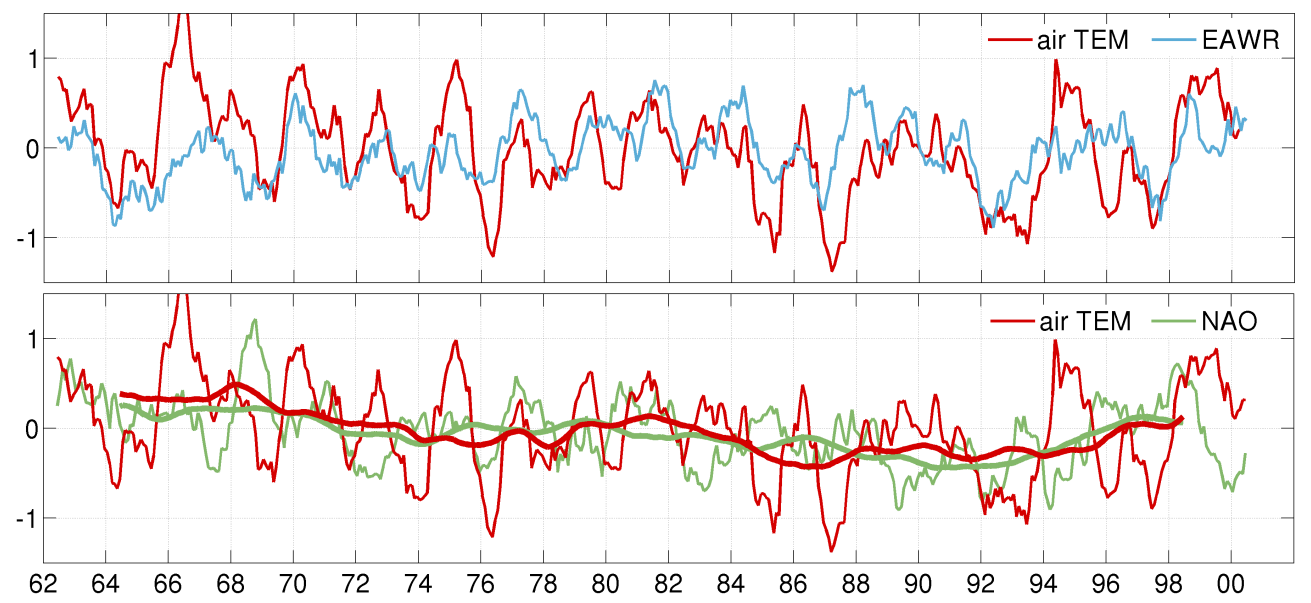

Figure 11: Evolution over 1962-2000 of the basin averaged AT (red), EA/WR (blue, upper panel) and NAO (green, lower panel) indexes after smoothing with 1-year (thin lines) and 5-year (bold lines) moving averages. On a short temporal scale (a), the variations of the AT follows those of the EA/WR oscillation while the longer scale ( $>5$ years) trends of AT follow the trends of the NAO index.

the possible existence of long term trend (over the 38 years of simulation) in the hydrodynamical variables and we propose some elements of answer to the complex issue of climate change impact on the Black Sea.

\subsection{Sea surface temperature}

[54] The most important mode of variability of the anomaly of SST occurs at basin scale and governs the short term oscillation of the dominant mode of variability of the MLD by impacting on the thermal stratification. This first mode of variability of the SST anomaly is closely related to the AT $(r=0.88$, Figure 12$)$, and follows both the rapid oscillation governed by the EA-WR index and the long term influence of the NAO (see section 5.3). The close response of SST to AT is modulated by the intensity of the Rim current (Figure 12): by deepening the MLD at basin scale, an intense Rim current enhances the thermal inertia of surface waters and reduces the response to AT changes $\left(0.55^{\circ} \mathrm{C}_{\text {sea }} /{ }^{\circ} \mathrm{C}_{\text {air }}\right.$ against $0.74{ }^{\circ} \mathrm{C}_{\text {sea }} /{ }^{\circ} \mathrm{C}_{\text {air }}$ in low Rim current conditions $)$.

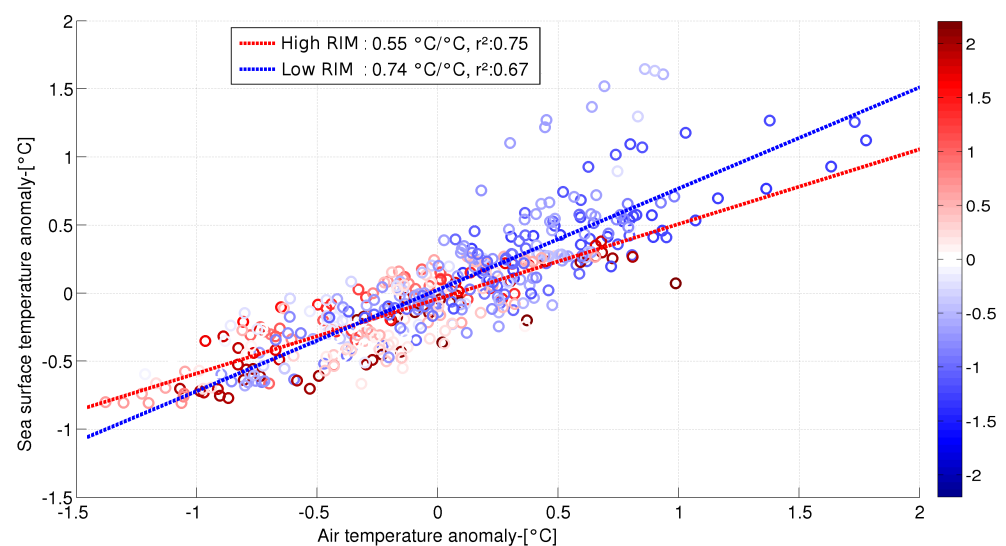

Figure 12: Scatter plot of SST-1 (Y-axis) against basin averaged AT (X-axis) anomalies. SST-1 scaling is chosen so that the value on the Y-axis represents the basin wide averaged SST anomaly. The color code represents the Rim current intensity (red: intense, blue: weak as estimated from MKE-1 temporal mode). The dotted lines represent the regressions computed over the months characterized by an intense or weak Rim current and illustrates the different response of SST to AT anomalies.

[55] The zonal repartition of SST anomaly (SST-2, Figure 5) is not significantly correlated with any circulation related variables (i.e. SLA, MKE) and is thus mainly governed by the repartition of the AT anomaly. Its influence on the CIL formation is discussed in section 6.3. 
[56] The meridionnal gradient of SST anomaly (SST-3) is related to the Rim current (Figure 6). This can be explained by considering the Rim current as a conveyor belt bringing warmer waters from the South to the North, and colder water from the North to the South. Interestingly, the whole shelf area is warmer when the Rim current is active. As the NWS is colder in general than the rest of the basin (not shown), this indicates that an intensified Rim current enhances the exchanges between the shelf and the open basin part. An important part of this exchange is mediated by the Sevastopol eddy (Figure 1) as already mentioned by Shapiro et al. (2010b).

\subsection{Sea level anomaly}

[57] SLA-1 is strongly related to the Rim current intensity (i.e. MKE-1 see Figure 6) and is also highly correlated with the basin wide averaged Mean Sea Level (MSL) $(r=-0.97)$. This suggests a closed link between the MSL and the Rim current as confirmed by the high (negative) correlation found between these two variables $(r=-0.86)$ and illustrated in Figure 13.

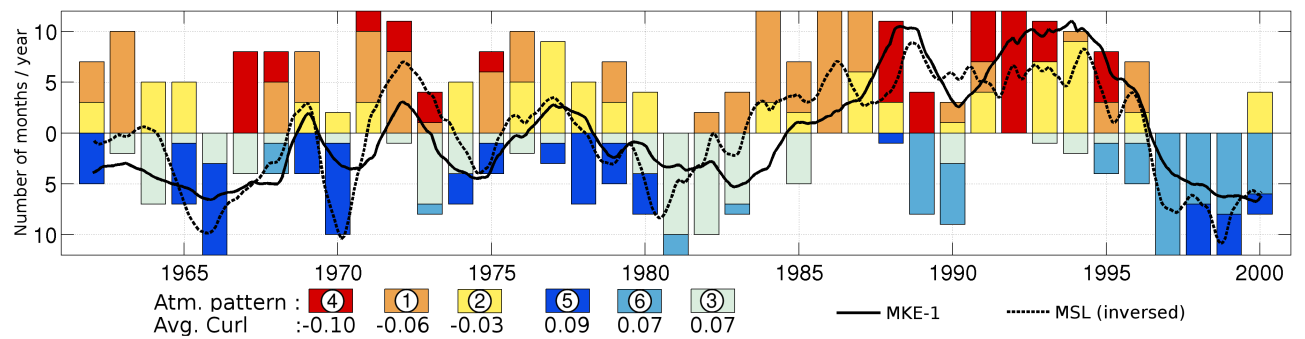

Figure 13: Temporal evolution over 1962-2000 of (1) the anomaly of the Rim current intensity (bold line, estimated from MKE-1 temporal evolution), (2) the anomaly of MSL (dotted line, scaled) computed from the modeled free surface elevation and inversed on the plot for facilitating the connection with the anomaly of the Rim current (i.e. a positive anomaly of MSL corresponds to a decrease of MSL). These two curves highlight that the variations of the anomalies of the (negative) MSL and the Rim current intensity are correlated $(r=0.86):$ the MSL decreases (resp. rises) during the active (resp. weak) phases of the Rim current intensity. Additionally, in order to assess the impact of the atmospheric patterns (more specifically of the wind curl) on the anomaly of the Rim current intensity, the bars present for each year the number of months mapped towards patterns 1, 2, 4 (characterized by cyclonic winds), 3, 5 and 6 (characterized by anticyclonic winds).

[58] This tight coupling between the interannual variations of the MSL and the Rim current intensity can be understood when considering the impact of the Rim current on the surface curvature. Intense Rim current increases the surface elevation in the periphery and decreases it in the central part. At interannual scales, the sea level at the Bosphorus entrance is mainly imposed by the quasi-direct (Staneva et al., 2001) balancing response of the Bosphorus barotropic transport. Therefore, considering that the sea level at the periphery is maintained, enhanced Rim circulation mainly results in a decrease of the central basin elevation, hence its averaged effect on the MSL. An important consequence of this tight coupling is that the long term variations of the Rim current intensity can be reconstructed based on the MSL signal, which can be retrieved from tide gauge data, as shown by Peneva et al. (2001).

[59] The second EOF of the SLA (not discussed in section 4) does not correspond to a physically independent mode (see Monahan et al. (2009) for a discussion on the physical interpretation of EOFs) and acts as a complement to SLA-1 to account for the part of MSL which is not directly linked to the Rim current but rather is linked to the water budget. The correspondence of this mode with the river discharges (which are the main terms of the Black Sea water budget (Stanev and Peneva, 2002)) is illustrated in Figure 14. The spatial pattern depicted by this mode is a consequence of this complementarity.

[60] Our interpretation of the main modes of variability of the SLA differs from that of Stanev and Peneva (2002); Grayek et al. (2010). For these authors, the first mode of SLA variability is only linked to the water budget (and not to the Rim current as shown here) while the second mode is connected to the Rim current due to its spatial pattern. These different conclusions can partly be explained by the different temporal scales considered in our study and in Stanev and Peneva (2002); Grayek et al. (2010). Indeed, here the seasonal cycle has been removed which is not the case in the other studies. This may change the interpretation of the variability of the SLA since at seasonal scales the time of adjustment through water exchanges to a rising of SLA in the Bosphorus area is not negligible anymore. However, the comparison of the EOFs associated to the modeled SLA (Figure 3) or its anomalies (Figures 6 and 14) shows that the removal of the seasonal cycle does not impact substantially on the spatial patterns depicted by the obtained EOFs. 


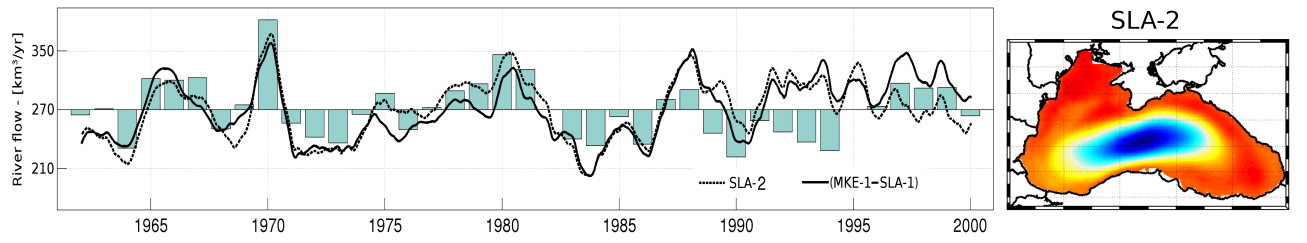

Figure 14: Left: Long term evolution of (1) the second EOF of the SLA (dotted line, scaled). (2) the difference between scaled MKE-1 and SLA-1 (bold line) which represents the part of MSL variability that is not accounted for by the variability of the Rim current and corresponds to the variability of the riverine flow (blue bars). Right : the spatial pattern of SLA-2.

\subsection{Cold intermediate layer}

[61] Figure 4 (right panel illustrating the temporal component of the EOF) shows that the dynamic of CCC is rather slow, in agreement with the scale of CIL waters renewal of 5.5 years found by Stanev and Staneva (2002).

[62] Interestingly the positive and negative phases of CCC correspond to similar phases of the intensity of the Rim current (MKE-1, Figure 6), suggesting that an intensified circulation favors the formation of CIW. Indeed, an intense Rim current accentuates the doming shape of the main pycnocline by intensifying the upwellings in the central part and the downwellings in the periphery. This enhanced curvature of the pycnocline has a positive impact on the CCC because (1) the formation of CIW waters is facilitated in the open basin by the outcropping of the deep isopycnals as shown by Stanev et al. (2003), and (2) the deepening of CIL along the periphery reduces its erosion by the summer heating.

[63] The second mode, CCC-2 (Figure 5), interestingly highlights and opposes the two main areas of CIW formation (cf. Introduction). Figure 5 indicates that the CCC in the southern part of the basin is mainly affected by the CIL waters formed on the NWS. Figure 15 illustrates that a positive anomaly of CCC-2 (stronger CIL formation in the open basin) is frequently associated to atmospheric conditions characterized by a higher positive anomaly of AT on the NWS compared to the open sea (i.e. patterns 4 and 6) while a negative anomaly of CCC-2 (stronger CIL formation on the NWS) is associated to a higher negative anomaly of the NWS AT compared to the rest of the basin (i.e. patterns 1 and 2).

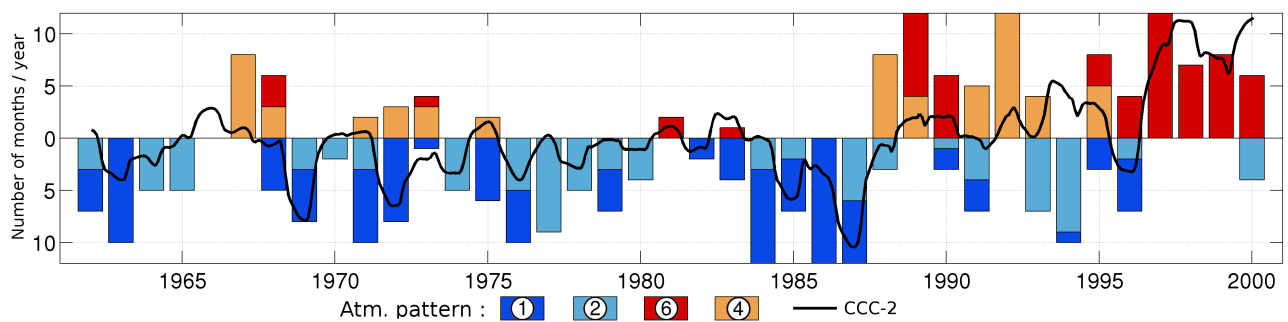

Figure 15: Long term evolution of the second temporal EOF mode of the CCC (bold line, CCC-2 shown in Figure 5). Positive (resp. negative) phases correspond to a relative enhancement of CIL formation in the open basin (resp. in the NWS). The histograms present for each year the number of months mapped towards patterns 1,2 (both characterized by a negative anomaly of the NWS AT), 4 and 6 (both characterized by a positive anomaly of the NWS AT).

\subsection{Impacts on the Black Sea environment}

[64] During the second part of the 80's and first part of the 90's, drastic environmental changes affected the Black Sea deep sea ecosystem. Among these changes are the sharp increase of phytoplankton blooms in the open basin (Yunev et al., 2003; Oguz, 2008), the outburst of the invasive ctenophore Mnemiopsis responsible for the 10-fold reduction of the biomass of copepods and other zooplankton in the late 1980s (Kovalev and Piontkovski, 1998; Shiganova, 1998), an increase in the inventory of sulfide and nutrients (ammonia, silicate, phosphate) in the anoxic zone and a decrease in the inventory of oxygen in the upper layer (Konovalov and Murray, 2001).

[65] Figures 6, (right panels), highlight that most of the physical variables present a singular behavior during the period 1985-1996. This is the case for SLA, MKE, MLD and CCC. 
[66] For instance, we note an important enhancement of the Rim current between 1983 (weak circulation) to 1988 (maximum circulation observed during 1962-2000). As explained previously (see section 6.3), enhancement of the Rim current is generally accompanied by an intensification of the CIL formation (see CCC-1 (Figure 6)). Additionally, during these particular years the enhancement of the Rim current coincides with an enhancement of the NWS specific CIL formation, as indicated by the strongly negative phase of CCC-2 (Figure 15). Since the Rim current and the NWS CIL formation and propagation are responsible for the exchanges of water and materials from the NWS to the deep basin, the intensification of these two processes during the second part of the 80's has promoted the export to the central basin of the products of eutrophication accumulated in the NWS waters and sediments during the long period of weak Rim current and high nutrient riverine discharge (late 70's and early 80's). These materials were then suddenly delivered to the open basin in 1985 and promoted phytoplankton blooms. Conversely, the general decrease of the deep basin phytoplankton biomass during the second part of the 90's corresponds to a general decrease of the Rim current intensity and to reduced CIL formation in the NWS.

[67] The different regimes of the Rim current may have had an important impact on the possibilities of fish larvae retentions and hence, may have played a role in the collapse of small pelagic fishes in favor to the invasive Mnemiopsi leydii.

\subsection{Climate change}

[68] Figures 4,5,6 and 11 show that none of the investigated variables (SST, MKE, MLD, CCC, AT) presents a consistent trend over the period 1962-2000.

[69] It has been shown (see section 5.3) that the SST trends follow the long term trends of the NAO index. If global warming affected the Black Sea during this period it was by impacting on the air masses circulation, as no AT trends superimposed to its relationship with the NAO can be evidenced. A displacement of the relative position of the teleconnection (see discussion in Hurrell and Deser (2010)) would probably affect the Black Sea response to teleconnection system phases, but as mentioned in section 5.3, the use of the NOAA times series does not allows to take into account these displacements.

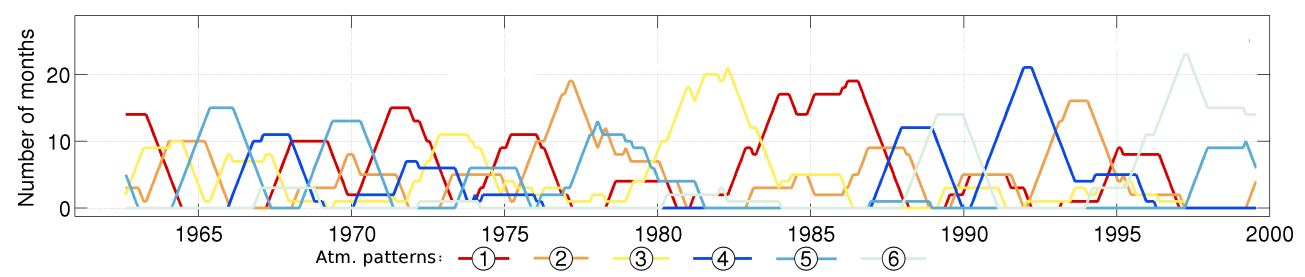

Figure 16: Evolution of the duration of the atmospheric anomalies shown in Figure 7, estimated as the number of months mapped towards each pattern (a color is attributed to each pattern) in a in a moving window of 2 years. An increase is observed in the duration of the anomalies regime. For example, the SOM pattern 6 lasted for almost two entire years (23 months over 24) between 1996 and 1998, while no patterns occurred more than 15 months over 24 before 1978.

[70] No increase of the occurence of a particular atmospheric anomaly pattern can be evidenced during this period neither. However, Figure 16 shows that the Black Sea is affected by "similar" (as identified by the SOM analysis) atmospheric conditions lasting over longer period after 1980. For instance, atmospheric patterns lasting more than a year occurred in 1986, 1992 and 1997 (Figure 16). This is of course not straightforward to connect this observed tendency to global warming and this trend has to be confirmed for the 2000-2010 decade.

[71] These types of long lasting anomalies regimes have the potentials to drive the system away from its average state. This occurred during the late 80's during which the Black Sea was affected during 5 years by dominant cold and cyclonic atmospheric anomalies (pattern 1, Figure 16) which led to the changes described in section 6.4.

\section{Conclusion}

[72] The long term (1962-2000) variability of the Black Sea hydrodynamics has been assessed using a 3D high resolution hydrodynamical model. First, the performances of the model in simulating the Black Sea physical properties at interannual scales have been assessed by comparing model outputs with multi-year satellite SST (1985-2000) and 
SLA (1993-2000). We chose to compare the dominant EOFs of modeled and satellite SST and SLA since this level of validation allows to assess the performances of the model in simulating surface variables but also the dynamics of connected hydrodynamical variables. The correlations between the modeled and satellite spatial and temporal dominant EOFs are most of the time significant and thus the model has the potentials to simulate the Black Sea physical processes at interannual scales. Model simulations have been performed over 40 years and the variability of SST,SLA, MLD, Rim current intensity and CCC were assessed and correlated. The synoptic perspective provided by the model approach allowed to evidence the preponderating role of the variability of the Rim current intensity in various aspects of the Black Sea hydrodynamics.

[73] In particular active (resp. weak) Rim current circulation was shown (1) to lower (resp. raise) the MSL. (2) to promote (resp. reduce) the CIL formation, being in this regard as effective as the Negative (resp. positive) SST anomalies. (3) to enhance (resp. reduce) the MLD and hence the thermal inertia of surface waters, reducing the SST response to AT anomalies, (4) to convey more (resp. less) effectively heat across the average SST meridional gradient. (5) to enhance (resp. reduce) the exchange between the NWS and the open basin.

[74] In order to connect the variability of the Black Sea hydrodynamics with that of atmospheric conditions over the Black Sea, spatial atmospheric fields (i.e. AT, wind stress and curl) have been analyzed during 1962-2000. Recurrent atmospheric patterns (i.e. various regimes of coincident AT and wind circulation anomalies) have been identified using a SOM analysis. The impact on these patterns of the NAO, EA/WR and ENSO oscillations has also been assessed.

[75] The study shows that the EA/WR and the NAO oscillations both impact on the AT, but with distinct time scales : the rapid oscillations of AT (1-5 years) are driven by the EA/WR oscillation which drives the meridional component of the winds, while on larger time scales ( $>5$ year), the AT variations follow those of the NAO oscillations, as was previously identified by Oguz et al. (2006). Both time scales of the AT variations are followed by the SST. We found no significant relationship between ENSO and the atmospheric patterns which does not imply that ENSO has no impact on the Black Sea SST but rather it means that if ENSO impacts the SST it is not through an AT anomaly resulting from modification of the winds pathways.

[76] It should be noted that the conclusions on the potential influence of large scale climate patterns on the Black Sea local atmospheric conditions are sensitive to the selected temporal and spatial scales (not) considered and this explains why our conclusions are in some points different from other studies. The study address the interannual variability of the Black Sea hydrodynamics.

[77] We have tried to connect the long term variability of the physical environment with that of the ecosystem and in particular, with the drastic environmental changes that occurred at the end of the $80 \mathrm{~s}$. We found that, during the period 1985-1995, the intensification of the Rim current and CIL formation process on the NWS have promoted the export to the central basin of the products of eutrophication accumulated in the NWS waters and sediments during the long period of weak Rim current and high nutrient riverine discharge (late 70's and early 80's). These materials were then suddenly delivered to the open basin in 1985 and promoted phytoplankton blooms. Conversely, the general decrease of the deep basin phytoplankton biomass during the second part of the 90's corresponds to a general decrease of the Rim current intensity. The different regimes of the Rim current may have had an important impact on the possibilities of fish larvae retentions and hence, may have played in the collapse of small pelagic fishes in favor to the invasive Mnemiopsi leydii.

[78] We also investigated the existence of a global trend in the hydrodynamical and atmospheric variables during 1962-2000. The only significant trend we found is an increase of the duration of persistent atmospheric anomalies regime over 1962-2000. These types of long lasting anomalies regimes have the potentials to drive the system away from its average state as exemplified by the pronounced enhancement of the Rim current at the end of the 80's as a consequence of a persistent cyclonic wind anomaly affecting the Black Sea over 5 years. This is of course not straightforward to assess whether this trend of an increase of long lasting atmospheric anomalies regimes is a consequence of climate change but if this tendency is confirmed, we could expect an intensification of the drastic changes affecting marine systems in response to the foreseen increasing global warming (Hansen et al., 2010).

[79] This increase instability of the physical environment may affect the ecosystems by making them more sensitive to human perturbations in the future. This underlines the utmost importance of preserving and promoting the ecosystem resilience(Costanza and Mageau, 1999) by a sound management, as it was already shown to be significantly affected in the Black Sea by human activity(Llope et al., 2011). 


\section{Acknowledgments}

[80] We thank Bruno Buongiorno Nardelli for kindly providing the processed SST satellite data, the AVISO program for the SLA images, and in particular Claire Dufau for her help in using these data. We thank the ECMWF for the providing of the atmospheric data. This research was supported by the SESAME project (EC Contract No GOCE036949) and was funded by the FNS-FNRS, Belgium. This is the MARE publication $n^{\circ} \mathrm{XXX}$.

\section{Bibliography}

\section{References}

Barth, A., Alvera-Azcárate, A., Rixen, M., Beckers, J.M., 2005. Two-way nested model of mesoscale circulation features in the Ligurian Sea. Progress In Oceanography 66, 171-189.

Beckers, J.M., 1991. Application of the gher 3d general circulation model to the western mediterranean. Journal of Marine Systems 1, 315-332.

Beckers, J.M., Gregoire, M., Nihoul, J.C.J., Stanev, E., Staneva, J., Lancelot, C., 2002. Modelling the danube-influenced north-western continental shelf of the black sea. i: Hydrodynamical processes simulated by 3-d and box models. Estuarine, Coastal and Shelf Science 54, 453-472.

Cherneva, Z., Andreeva, N., Pilar, P., Valchev, N., Petrova, P., Soares, C.G., 2008. Validation of the wamc4 wave model for the black sea. Coastal Engineering 55, 881-893. Hindcast of Dynamic Processes of the Ocean and Coastal Areas of Europe.

CNES, 2011. SSALTO/DUACS User Handbook: (M)SLA and (M)ADT Near-Real Time and Delayed Time Products. AVISO.

Costanza, R., Mageau, M., 1999. What is a healthy ecosystem? Aquatic Ecology 33, 105-115. 10.1023/A:1009930313242.

Delhez, E., 1996. Reconnaissance of the general circulation of the north-western european continental shelf by means of a three-dimensional turbulent closure model. Earth-Science Reviews 41, 3-29.

Ginzburg, A., Kostianoyu, A., Sheremet, N., 2004. Seasonal and interannual variability of the black sea surface temperature as revealed from satellite data (1982-2000). Journal of Marine Systems 52, 33-50.

Grayek, S., Stanev, E., Kandilarov, R., 2010. On the response of Black Sea level to external forcing: altimeter data and numerical modelling. Ocean Dynamics 60, 123-140.

Grégoire, M., Beckers, J., Nihoul, J., Stanev, E., 1998. Reconnaissance of the main black sea's ecohydrodynamics by means of a 3d interdisciplinary model. Journal of Marine Systems 16, 85-105.

Grégoire, M., Friedrich, J., 2004. Nitrogen budget of the northwestern black sea shelf inferred from modeling studies and in situ benthic measurements. Mar Ecol Prog Ser 270, 15-39. 10.3354/meps270015.

Hansen, J., Ruedy, R., Sato, M., Lo, K., 2010. Global surface temperature change. Rev. Geophys. 48, RG4004.

Hurrell, J.W., Deser, C., 2010. North atlantic climate variability: The role of the north atlantic oscillation. Journal of Marine Systems 79, 231-244. Impact of climate variability on marine ecosystems: A comparative approach.

Kara, A.B., Helber., R.W., Boyer, T.P., Elsner, J.B., 2009. Mixed layer depth in the aegean, marmara, black and azov seas: Part 1: General features. Journal of Marine Systems 78, S169-S180.

Kara, A.B., Wallcraft, A.J., Hurlburt, H.E., 2007. A correction for land contamination of atmospheric variables near land-seas boundaries. Journal of Physical Oceanography 37, 803-818.

Kazmin, A.S., Zatsepin, A.G., 2007. Long-term variability of surface temperature in the Black Sea, and its connection with the large-scale atmospheric forcing. Journal of Marine Systems 68, 293-301.

Kohonen, T., 1998. The self-organizing map. Neurocomputing 21, 1-6.

Konovalov, S., Murray, J., 2001. Variations in the chemistry of the black sea on a time scale of decades (1960-1995). Journal of Marine Systems $31,217-243$.

Korotaev, G., Oguz, T., Nikiforov, A., Koblinsky, C., 2003. Seasonal, interannual, and mesoscale variability of the black sea upper layer circulation derived from altimeter data. Journal of geophysical research 108, 3122.

Kovalev, A.V., Piontkovski, S.A., 1998. Interannual changes in the biomass of the black sea gelatinous zooplankton. Journal of Plankton Research 20,1377-1385. http://plankt. oxfordjournals.org/content/20/7/1377.full.pdf+html.

Krichak, S.O., Kishcha, P., Alpert, P., 2002. Decadal trends of main eurasian oscillations and the eastern mediterranean precipitation. Theoretical and Applied Climatology 72, 209-220. 10.1007/s007040200021.

Kutiel, H., Benaroch, Y., 2002. North sea-caspian pattern (ncp) - an upper level atmospheric teleconnection affecting the eastern mediterranean: Identification and definition. Theoretical and Applied Climatology 71, 17-28. 10.1007/s704-002-8205-x.

Langmead, O., McQuatters-Gollop, A., Mee, L.D., Friedrich, J., Gilbert, A.J., Gomoiu, M.T., Jackson, E.L., Knudsen, S., Minicheva, G., Todorova, V., 2009. Recovery or decline of the northwestern Black Sea: A societal choice revealed by socio-ecological modelling. ECOLOGICAL MODELLING 220, 2927-2939.

Llope, M., Daskalov, G.M., Rouyer, T.A., Mihneva, V., Chan, K.S., Grishin, A.N., Stenseth, N.C., 2011. Overfishing of top predators eroded the resilience of the black sea system regardless of the climate and anthropogenic conditions. Global Change Biology 17, 1251-1265.

Ludwig, W., Dumont, E., Meybeck, M., Heussner, S., 2009. River discharges of water and nutrients to the mediterranean and black sea: Major drivers for ecosystem changes during past and future decades? Progress In Oceanography 80, 199-217.

Mamaev, V., Zaitsev, Y., 1997. Marine biological diversity in the Black Sea : A study of change and decline. volume optional of optional. United Nation Publications, New York. optional edition. Optional.

Monahan, A.H., Fyfe, J.C., Ambaum, M.H.P., Stephenson, D.B., North, G.R., 2009. Empirical orthogonal functions: The medium is the message. J. Climate 22, 6501-6514. Doi: 10.1175/2009JCLI3062.1. 
Nardelli, B.B., Colella, S., Santoleri, R., Guarracino, M., Kholod, A., 2010. A re-analysis of black sea surface temperature. Journal of Marine Systems 79, 50-64.

Niermann, U., Kideys, A.E., Kovalev, A., Melnikov, V., Belokopytov, V., 1999. Fluctuations of pelagic species of the open black sea during 19801995 and possible teleconnections, in: Besiktepe, S., Unluata, U., Bologa, S. (Eds.), Environmental degradation of the Black Sea: Challenges and Remedies.. Kluver Academic Publishers, pp. 147-173.

Oguz, T. (Ed.), 2008. State of the Environment of the Black Sea (2001 - 2006/7). Publications of the Commission on the Protection of the Black Sea Against Pollution (BSC).

Oguz, T., Dippner, J.W., Kaymaz, Z., 2006. Climatic regulation of the black sea hydro-meteorological and ecological properties at interannual-todecadal time scales. Journal of Marine Systems 60, 235-254.

Oguz, T., Gilbert, D., 2007. Abrupt transitions of the top-down controlled Black Sea pelagic ecosystem during 1960-2000: Evidence for regimeshifts under strong fishery exploitation and nutrient enrichment modulated by climate-induced variations. Deep-Sea Research Part I - Oceanographic Research Papers 54, 220-242.

Peneva, E., Stanev, E., Belokopytov, V., Le Traon, P.Y., 2001. Water transport in the bosphorus straits estimated from hydro-meteorological and altimeter data: seasonal to decadal variability. Journal of Marine Systems 31, 21-33.

Richardson, A.J., Risien, C., Shillington, F.A., 2003. Using self-organizing maps to identify patterns in satellite imagery. Progress In Oceanography 59, 223-239. ENVIFISH: Investigating environmental causes of pelagic fisheries variability in the SE Atlantic.

Shapiro, G.I., Aleynik, D.L., Mee, L.D., 2010a. Long term trends in the sea surface temperature of the black sea. Ocean Science 6, $491-501$.

Shapiro, G.I., Stanichny, S.V., Stanychna, R.R., 2010b. Anatomy of shelf-deep sea exchanges by a mesoscale eddy in the north west black sea as derived from remotely sensed data. Remote Sensing of Environment 114, 867-875.

Shiganova, T.A., 1998. Invasion of the black sea by the ctenophore mnemiopsis leidyi and recent changes in pelagic community structure. Fisheries Oceanography 7, 305-310.

Stanev, E., Bowman, M., Peneva, E., Joanna., S., 2003. Control of black sea intermediate water mass formation by dynamics and topography: Comparison of numerical simulations, surveys and satellite data. Journal of Marine Research 61, 59-99(41).

Stanev, E., Staneva, J., 2002. Watermass formation in the black sea during 1991-1995. Journal of Marine Systems 32, $199-218$.

Stanev, E.V., Peneva, E.L., 2002. Regional sea level response to global climatic change: Black sea examples. Global and Planetary Changes 32, $33-47$.

Staneva, J., Dietrich, D., Stanev, E., Bowman, M., 2001. Rim current and coastal eddy mechanisms in an eddy-resolving black sea general circulation model. Journal of Marine Systems 31, 137-157.

Vandenbulcke, L., Capet, A., Beckers, J.M., Grégoire, M., Besiktepe, S., 2009. An operational implementation of the GHER model for the Black Sea, with SST and CTD data assimilation. Ocean Science Discussions 6, 1895-1911.

Von Storch, H., Zwiers, F., 1999. Statistical Analysis in Climate Research. Cambridge University Press.

Yunev, O.A., Suetin, V., Suslin, V., Moncheva, S., 2003. Long-term changes in the Black Sea surface chlorophyll a according to in situ and modern satellite data. Elsevier. volume Volume 69. pp. 168-173.

\section{Appendix A. Construction of the anomalies compared to a climatological seasonal cycle}

[81] Construction of the climatological seasonal cycle: The climatology consists of 366 daily climatological fields and is computed for each day by averaging all the fields present within a 20 day moving window, over the whole period (e.g. 38 years). In the case of model results, for example, each field corresponds to a weekly average. When the corresponding week is only partly covered by the averaging window its contribution to the average is weigthed proportionally to the part of the week covered by the averaging window.

[82] Computation of the anomalies : For each original weekly or monthly average field, the anomaly is produced by subtracting from this field the average of the climatological corresponding days.

\section{Appendix B. Empirical Orthogonal Functions}

[83] Each hydrodynamical variable considered in this study is decomposed into its Empirical Orthogonal Functions (EOFs). The EOFS are orthogonal spatial patterns that can be thought of as empirically derived basis functions. The time coefficients obtained by projecting the observed field onto the EOFs are uncorrelated and represent the variability of the field efficiently (Von Storch and Zwiers, 1999)

[84] The EOFs are ordered according to the part of the original signal's variance they represent. Usually, only a few EOFs are required to describe most of the variability of the original variables.

[85] In some circumstances, the spatial modes have a physical meaning and represent the main processes affecting the evolution of the variable but this is, however, not systematically true (Monahan et al., 2009), and the EOFs should in general rather be viewed as axis of main variability allowing a more convenient description of the variable's evolution. [86] There are several options concerning the normalization of the EOFs. When a mode is homogeneous in sign, this mode is normalized by its basin scale average implying that the spatial average of this mode is 1 and its temporal mode gives directly the basin average of the variable (e.g. the temporal mode associated to SST-1 shown in Figure 4 
directly gives the basin wide average of the SST anomaly). Other EOFs are normalized in order to have a standard deviation of the temporal mode equals to 1.

\section{Appendix C. Definition of the hydrodynamical variables}

[87] The mixed layer depth (MLD) is retrieved by linear interpolation of the density profile. It is defined (Kara et al., 2009) as the first depth where a density difference of $\Delta \rho=0.125 \mathrm{~kg} / \mathrm{m}^{3}$ compared to the density at $3 \mathrm{~m}$ is found. MLD is expressed in meters counted negatively from the surface.

[88] The CIL Cold Content (CCC) (Stanev and Staneva, 2002) corresponds to $\int(T-8) d z$, where $\mathrm{T}$ is the temperature in ${ }^{\circ} \mathrm{C}$, and the integration is carried out between the upper and lower $8^{\circ} \mathrm{C}$ isotherms.

[89] The Mean Kinetic Energy (MKE), $\frac{1}{2} \rho u^{2}$, where $\rho$ is the density and $u$ the norm of mean velocity, is vertically averaged over the upper $100 \mathrm{~m}$.

\section{Appendix D. Self Organizing Maps (SOM)}

[90] We refer to Kohonen (1998) for a mathematical description of the SOM algorithm, and to Richardson et al. (2003) for an illustration of the ways it can be used in oceanography.

[91] The SOM algorithm allows to identify from an initial set of vector elements a subset of vector (the "typical“" patterns) optimally representative of the initial set distribution. In the present case, for example, each initial element consist of the fields of AT, wind curl, zonal and meridional component anomalies of one particular month, gathered in a single vector. The representative patterns are those presented in Figure 7. The key issue is that it allows to reduce the dimensionality of the initial dataset to a discrete number (chosen prior the analysis) of representative patterns, which facilitates the analysis of the initial dataset. In this case, the SOM analysis allows us to refer to one of the six identified pattern wich are multivariate and contain spatial information, rather than, for example, to the averaged AT.

[92] The procedure allows then to map each element toward one of the representative patterns, based on euclidean distance considerations. As in our case each element corresponds to one month it allows us in particular to relate the teleconnection monthly time series to the identified atmospheric patterns.

[93] If the distribution associated to one pattern, amongst the positive and negative phases of a given teleconnection, is significantly different from a random distribution, it indicates a relationship between the occurrence of this pattern and a given phase of the teleconnection.

[94] As some patterns occurs more often than others, however, the significance of uneven distribution is not the same for each pattern. In order to provide a quantified appreciation of this significance, we assess, for each pattern, the probability of getting the observed distribution for a number of trials equal to this pattern occurrence and under the hypothesis that each trial as an equal probability of being positive or negative. 